\title{
Correlation of the Rates of Solvolyses of Cinnamyl Bromide
}

\author{
In Sun Koo, ${ }^{*}$ Jun Mi Cho, Sun Kyoung An, Kiyull Yang, Jong Pal Lee, ${ }^{\dagger}$ and I. Lee \\ Department of Chemical Education and The Research Institute of Nathal Science. \\ Gyeongsang National Universily. Jinin 660-701, Korea

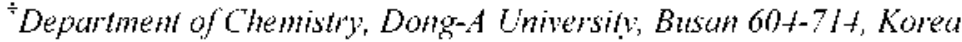 \\ Department of Chemistry, Ih ha Universily, lncheon $102-751$. Korea
}

Received Jamuary /5, 2003

\begin{abstract}
Solvolytic rate constants at $25^{\circ} \mathrm{C}$ are reported for solvolyses of cinnamyl bromide (1) in binary mixtures of water with acetone, ethanol, methanol, methanol- $d$, and 2,2,2-trifluoroethanol. Product selectivities are reported for solvolyses of $\mathbf{l}$ in aqueous ethanol and methanol. Rate ratios in solvents of the same $Y_{k,}$ value and different nucleophilicity provide measures of the minimum extent of nucleophilic solvent assistance ( $e . g$. $\left[k_{\text {HOFW }} / k_{15 T F F}\right]_{y}=2.88, \mathrm{EW}=$ ethanol-water). With use of the extended Grunwald-Winstein equation, the $/$ and $m$ values are similar to the values of 0.43 and 0.88 obtained for the solvolyses of 1 using the equation (see below) which includes a parameter $(h$ for solvation of aromatic rings. The masnitude of $l$ and $m$ values associated with a change of solvent composition predicts the $S_{x} 1$ reaction mechanism rather than an $S_{* 2}$ channel.

Product selectivities $(S)$, defined by

$\mathrm{S}=$ [ether product] $/[$ alcohol product $] \times[$ water] $/[$ alcohol solvent $]$

are related to four rate constants for reactions involving one molecule of solvent as nucleophile and another molecule of solvent as general base catalyst. A linear relationship between $1 / \mathrm{S}$ and molar ratio of solvent is derived theoretically and validated experimentally for solvolyses of the above substrates from water up $75 \%$ ]$/ \mathrm{S}=\left(k_{\mathrm{wat}} / k_{\mathrm{aw}}\right)([$ alcohol solvent $][$ water $])+k_{\mathrm{ww}} / k_{\mathrm{aw}}$

alcohol-water. The results are best explained by product formation from a "free" carbocation intermediate rather than from a solvent-separated ion pair.
\end{abstract}

Key Words : Solvolysis, Selectivity, General base catalyst, Solvent-separate ion pair

\section{Introduction}

Dispersion into separate lines in the correlation of the specific rates of solvolysis of a substrate in various binary mixtures was documented ${ }^{1-5}$ in earlicr treatments using the Grunwald-Winstein Eqn. (1). ${ }^{6-11}$

$$
\log \left(k / k_{0}\right)=m Y-c
$$

ln general, dispersion effects in unimolecular solvolysis ${ }^{10.11}$ make smaller contributions to the overal linear frec energy relationships (LFER) than solvent nucleophilicity eflects in bimolecular solvolysis. ${ }^{6.12}$ It was suggested that a sccond term which is governed by the sensitivity $l$ to solvent nucleophilicity $N$, should be added to Eqn. (1) for bimolecular solvolysis. ${ }^{2}$ The resulting Eqn. (2) is often referted to as the extended Grunwald-Winstein equation. ${ }^{12}$

$$
\log \left(k / k_{0}\right)=m Y+l N-c
$$

Kevill ef al., recently suggested that, since the dispersion seems to follow a consistent pattern. it should be possible to develop an aromatic ring parameter (I). which, as qualilied by the appropriate sensitivity ( $h$ ), can be added to Eqns. (1) or (2) 10 give Eqns. (3) or (4), respectively. ${ }^{13-16}$

$$
\begin{gathered}
\log \left(k / k_{0}\right)=\mathrm{m} Y+h l-c \\
\log \left(k / k_{0}\right)-\mathrm{m} \gamma-l N+h-c
\end{gathered}
$$

Solvolytic reactions in alcohol-water mixtures lead 10 alcohol and ether products from which selectivities can be calculated using Eqn. (5). ${ }^{17-19}$

$$
\mathrm{S}=\frac{\mid \text { ether product } \mid}{[\text { alcohol produc1 }]} \times \frac{\mid \text { water } \mid}{[\text { alcohol solven1 }]}
$$

Nucleophilic atlack may occur on 'free' carbocations. solvent-separated ion pairs or possibly contact ion pairs, and the solvent-dependence of $S$ may be due to changes in the nature of the intermediate leading 10 product. $^{19.20} \mathrm{An}$

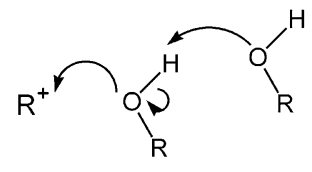

(i) $k_{\text {aa }}$

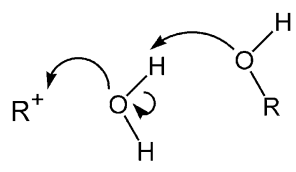

(iii) $k_{\text {wa }}$

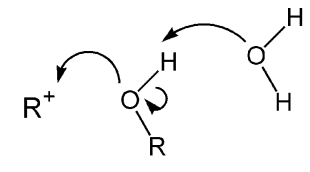

(ii) $k_{\text {aw }}$

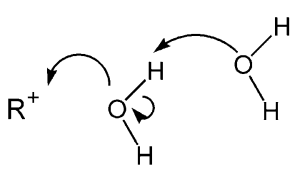

(iv) $k_{\mathrm{ww}}$
Scheme 1. Gencral base catalyzed ractions for nucleophilic attack on carhocations. 
altemative explanation involving nucleophilic attack solcly on 'free' carbocations is given below to account for the solvent dependence of $S$ for $S 1$ reactions. ${ }^{19}$

If nucleophilic attack by one solvent molecule were assisted by a second molecule of solvent acting as general base, in alcohol-water mixtures there will be four competing product-delemining steps (Seheme 1) delined by the following third order rate constants: $k_{u x}$ in which water is both nucleophile and general base: $k_{\text {aw }}$, the alcohol solvent acts as nucleophile and water acts as general base; $k_{\text {wa }}$, water acts as nucleophile and alcohol acts as general base: $k_{\text {aa }}$. alcohol acts as both nucleophile and general base. ${ }^{19}$

Scheme 1 is of the same kinclic form as the one we have previously derived for acyl ${ }^{2 l \text { ti. } 2 l b}$ and sulfonyl ${ }^{2 l c}$ transfer reactions which are shown to procecd by $\mathrm{S}_{2}$ or $\mathrm{S}_{11} \mathrm{~N}$ reaction mechanisms. " However, we reported the new relationship between $S$ and solvent composition for $S_{x}$ reactions involving nucleophilic attack on carbocations and general base catalysis. ${ }^{19}$ It should be noted that in an $\mathrm{S} \times 2$ processes the rate determining and product determining steps are the same, while in the $S$ processes the rate depends on the ionizing power of the solvent but the product is determined by the attack of solvent on the cationic intermediate, $\mathrm{R}^{-}$, i.e.. the rate determining and product detemining steps are not the same. We assume that the rates of product-determining reactions shown in Scheme $I$ are given by third order rate constants multiplied by the appropriate molar concentrations of solvent. II, in highly aqucous media, $k_{\text {aw }} \mid$ water $] \mid \mathrm{ROH}\left[\left|>k_{\mathrm{aa}}\right| \mathrm{ROH}[]^{2}\right.$, the relationship given in Eqn. (6) can readily be derived. ${ }^{21}$ ?

$$
1 / \mathrm{S}=\left(k_{\mathrm{wwa}} / k_{\mathrm{aw}}\right)([\mathrm{a} \text { cohol solvent }] /[\text { water }])+k_{\mathrm{wv}} / k_{\mathrm{tw}}
$$

The intercept of Eqn. (6) implies that the maximum $S$ value in highly aqueous media is determined by the ratio of third order rate constants $k_{\mathrm{aw}} / k_{\mathrm{u}}$; this ratio represents the rate of nucleophilic attack by alcohol compared with the rate of nuclcophilic attack by water, in water as solvent and with water acting as a general base catalyst.

It has been shown that the plot of $1 / \mathrm{S}$ versus [cosolvent] |water| (Eqn. 6) lead to a straight line of positive slope ( $k_{w a}$; $k_{\text {aw }}$ ) in the general base catalysed (Scheme 1) solvolysis of acyl halides in which the $k_{\mathrm{ws}}$ (and/or $k_{\mathrm{aw}}$ ) term is impotant in the product formation step. ${ }^{|c|}$, The main putpose of the work described in this paper is to test whether there is a linear relationship between $1 / S$ and the alcohol/water molar ratio, as predicted by Equ. (6) for the product-detcrmining step of $\mathrm{S}_{\mathrm{N}} 1$ reaction of carbocations. Previous work has been restricted to solvolyses of $p$-methoxybenzyl and diphenylmethyl chlorides. "l

Suitable substrates on which to test Eqn. (6) are those which reacl only by substitution pathways via "free" carbocations." $\Lambda$ lso, the substrates should permit rapid mixing in highly aqueous mixtures, and should not be so reactive that their solvolyses are interlacial. ${ }^{4}$ We chose cinnamyl bromide (1) as a suitable substrate which reacts only is expected to react through an $S_{*} 1$ pathway via 'liec' carbocation in view of the stable cationic form. $\mathbf{1}^{-}$.

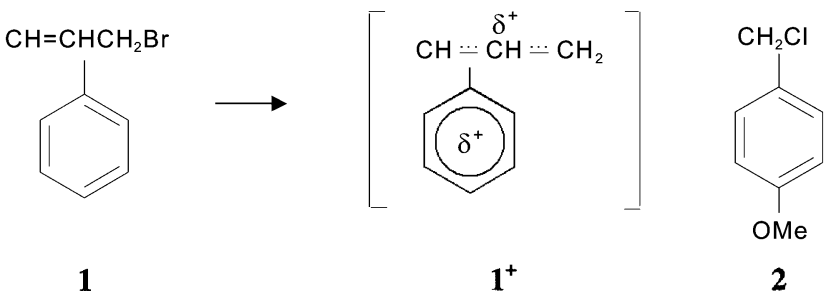

In this work, we determined rate constants for solvolyses of 1 in aqueous binary mixlures of acetone, ethanol, methanol, methanol- $d .97 \%$ TFE $(w / w)$ and pure water at $25.0^{\circ} \mathrm{C}$, and the transition state variation is discussed by applying the Grunwald-Winstein equation, extended Grunwald-Winstein equation, aromatic ring parameter equation and kinctic solvent isotope elfect. We test whether there is a linear relationship between $I / S$ and the alcohol water molar ratio, as predicted by Eqn. (6) for the product-determining step of $\mathrm{S} .1$ reactions.

\section{Results}

Rate constants for solvolyses of 1 in aqueous binary mixtures of acetone, chanol, methanol, methanol-d. water, $\mathrm{NaClO}_{4}$, and $\mathrm{LiBr}$ in 90McOIJ, TFE-water (\%w/w) and TFE-ethanol (\%v/v) a1 25.0 "C are reported in Tables 1.2 and 3 , and results at various temperatures are given in Table 4 along with the corresponding $A$ rthenius parameters.

Selectivity data were obtained from product analyses as soon as possible alter completion of 10 half-lives of reaction." Selectivity data for solvolyses of $\mathbf{1}$ in ethanolwater and methanol-water mixtures at $25.0^{\circ} \mathrm{C}$ are given in Table 5 .

\section{Discussion}

Kinetic Data. For binary solvents having the same $\% \mathrm{v} / \mathrm{v}$ water, rate constants (Table I) increase in the order acetone-

Table 1. Rate constants $\left(k \cdot \mathrm{s}^{-1}\right)$ for solvolyses of cinnamyl bromide (1) in agueous binary mixtures at $25^{\circ} \mathrm{C}$.

\begin{tabular}{rccc}
\hline \multirow{4}{*}{$* \% \%$} & MeOII & I:LII & Acelone \\
\cline { 2 - 4 } & \multicolumn{3}{c}{$k \times 10^{3}$} \\
90 & $0.113^{\circ}$ & 0.0156 \\
80 & 0.514 & 0.113 & \\
70 & 1.87 & 0.478 & 0.0287 \\
60 & 6.04 & 1.31 & 0.0168 \\
50 & 17.6 & 3.40 & 0.741 \\
40 & 41.5 & 12.5 & 3.21 \\
30 & 113 & 39.2 & 15.6 \\
20 & 304 & 269 & 59.7 \\
10 & 393 & 393 & 206 \\
$\mathrm{H}_{2} \mathrm{O}$ & 445 & 434 & 382 \\
\hline
\end{tabular}

"Determined conductimetrically at least in duplicate: typical error $+3 \%$. Solvolyses in MeOD) give $\$-0.0890(+0.10) \times 10^{-3} \mathrm{~s}^{-1}$ giving a kinetic solvent isotope effect of 1.27 . 
Table 2. Rate constants $\left(k, \mathrm{~s}^{-1}\right)$ for solvoly ses of cinnamyl bromide (1) in 2,2,2,-1rilluoroethanol binar, mixlures at $25^{\circ} \mathrm{C}$

\begin{tabular}{|c|c|c|c|}
\hline \multirow{2}{*}{$w w_{0}^{0}$} & $\mathrm{TFE}-\mathrm{H}_{2} \mathrm{O}$ & \multirow{2}{*}{$v v_{0}^{0}$} & TFE-EtOH \\
\hline & $k \times 1 b^{2}$ & & $k \times \mathrm{It}^{3}$ \\
\hline $97 \mathrm{ll} 1 \mathrm{l}-31 \mathrm{1}_{2} \mathrm{O}$ & 15.3 & 80 Tlit: - 20) J $10 \mathrm{H}$ & 2.36 \\
\hline 90 Tlit: - 1011-0 & 31.5 & 6) Tlit: - 40 JitOH & 0.493 \\
\hline $70 \mathrm{~T}] \mathrm{l}]:-3011_{2}(0$ & 66.4 & 40 [li]: - 60) JitoH & 0.132 \\
\hline $50+[1]:-5011_{2}(0)$ & ]108 & 20 laje- 0 ktol] & $0 .(140) 0$ \\
\hline
\end{tabular}

"Determined conductimetrically at least in duplicate: typical error $\pm 33^{\circ} 0$.

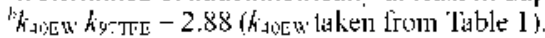

Table 3. Rate constants ( $k, s^{3}$ ) lor solvoly ses of cimlannel bromide (1) in salt solution in $90 \%$ methanol-10\% water binary mixilures at $25^{\circ} \mathrm{C} \mathrm{C}$

\begin{tabular}{cc}
\hline Added salts (Conen. M) & $k \times 1 t^{\hat{y}}$. sec ${ }^{3}$ \\
\hline $0.01 \mathrm{M} \mathrm{LiBr}$ & 0.577 \\
$0.003 \mathrm{M} \mathrm{LiBr}$ & 0.547 \\
$0.01 \mathrm{M} \mathrm{NaClO}$, & 0.589 \\
$0.003 \mathrm{M} \mathrm{NaClO}_{1}$ & 0.523 \\
\hline
\end{tabular}

"Determined litimetrically at least in duplicate: lypical error 15 " o.

Table 4. Additional rale conslants $\left(k s^{-1}\right)$ for solvolyses of cinnamyl bromide (1) in acjucous alcohol mixilures and the activation parameters calculated using data at 35 and $45^{\circ} \mathrm{C}$

\begin{tabular}{|c|c|c|c|c|}
\hline & $\mathrm{T} " \mathrm{C}$ & $k \mathrm{ss}^{3}$ & $\Delta I^{+} \mathrm{kcal} \mathrm{mol}^{3}$ & $\Delta S^{+}$cal mol ${ }^{\prime} K^{\prime}$ \\
\hline $70_{0}^{0} \mathrm{EtOH}$ & $35^{\circ} \mathrm{C}$ & $4.83 \times 10^{3}$ & 20.5 & -0.932 \\
\hline $70_{0}^{0} \mathrm{EtOH}$ & $45^{\circ} \mathrm{C}$ & $1.3 .3 \times 10^{2}$ & & \\
\hline $70_{0}^{0} \mathrm{McOH}$ & $35^{\circ} \mathrm{C}$ & $1.68 \times 10^{2}$ & 18.3 & -5.14 \\
\hline $70_{0}^{0} \mathrm{McOH}$ & $45^{\circ} \mathrm{C}$ & $4.88 \times 10^{2}$ & & \\
\hline $90_{0}^{0} \mathrm{McOH}$ & $35^{\circ} \mathrm{C}$ & $1.67 \times 10^{3}$ & 19.8 & -5.15 \\
\hline $90_{0}^{0} \mathrm{McOH}$ & $45^{\circ} \mathrm{C}$ & $4.86 \times 10^{2}$ & & \\
\hline
\end{tabular}

$\mathrm{H}_{2} \mathrm{O}<$ ethanol $-\mathrm{H}_{2} \mathrm{O}<$ methanol- $\mathrm{H}_{2} \mathrm{O}$. The rates increase appreciably as the water content of a mixture increases, thus the rate is the highest in the solvents with high ionizing power $I$. suggesting extensive bond breaking in the transition state. First-order rate constants for solvolyses of $\mathbf{1}$ vary over $3.2 \times 10^{-}$-fold in alcohol-water mixtures, whereas the observed first-order rate constants for phenyl chloroformates, which is known to react wia an $\mathrm{S}_{* 2}$ like $\mathrm{S}_{\mathrm{i}} \mathrm{N}$ or carbony $l$ addition-elimination reaction mechanism vary only over 20 -fold. 6.2 These results indicate that the rate-determining step is not the bond formation step which was found in the reaction of phenyl chloroformates but the bond breaking step for the reaction of $\mathbf{1}$ where the transition state is sensitive to solvent ionizing power. These results are very similar to those of solvolytic reactions of $p$-methoxybenzoyl chloride ${ }^{2 ? 3 x}$ cinnamyl chloride ${ }^{2315}$ and thenoyl chloride but they are different from the results of solvolytic reactions of $p$-nitrobenzoyl chloride ${ }^{-11: 25} p$-nitrobenzenesulfonyl chloride ${ }^{1.21}$ and furoyl chloride. ${ }^{\text {: }}$

The close similarity of the rate-determining step for solvolyses of 1. $p$-methoxybenzyl chloride (2) and cinnamyl chloride is shown by similar solvent kinetic isotope effects in methanol (1.27 for 1, 1.22 for 2 . and 1.11 for cimnamyl

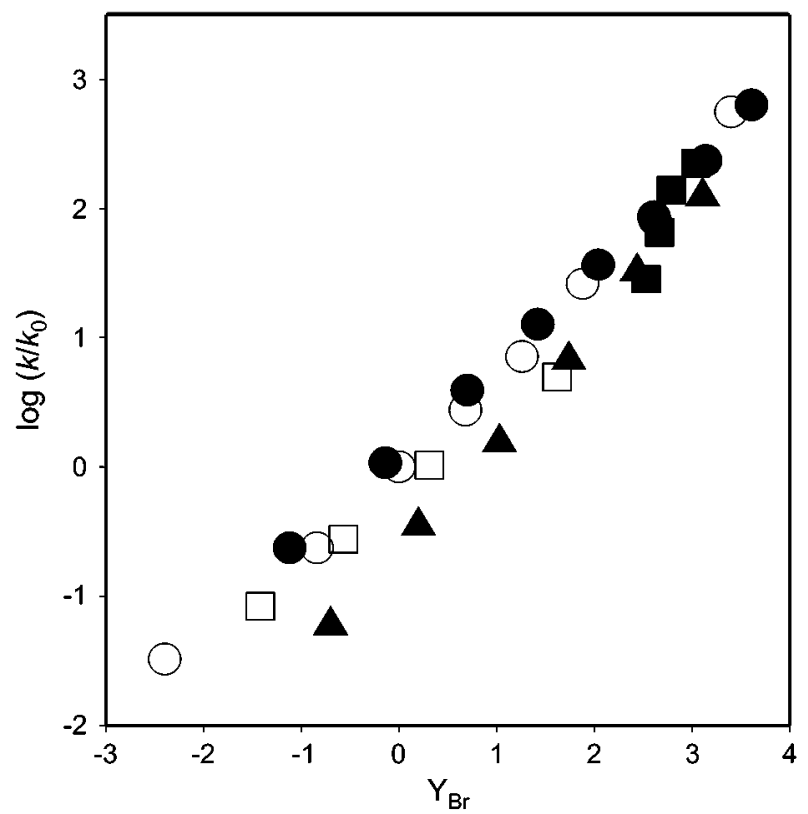

Figure 1. Logarithms of lirst-order rate constants for solvolysis of cinnamyl bromide at $25{ }^{\prime \prime} \mathrm{C}: \log \left(k k_{0}\right)$ us. $\mathrm{Y}_{\mathrm{Br}}$ (solvent code: methanol: $\because$, ethanol: 4 , acetone: $\mathbf{\text { aTFF}}-\mathrm{H}_{2} \mathrm{O}: \sqsubset$, TFF.-FtOH).

chloride: see footnote in Table 1$)^{2.3}$ and by the very simular rate-rate profiles of solvent effects on reactivity (Fig. 3). Extensive studies have been made of solvent isotope effects in water. but relatively little has been published for methanol. ${ }^{3.3 z^{-}}$The value of 1.27 (footnote in Table 1) is in the range expected for an $\mathrm{S}_{\mathrm{N}} \mathrm{l}$ reaction mechanism. ${ }^{-3}$ Also, similar solvent isotope effects in water and methanol have previously been obtained for solvolyses of acetic anhydride. -

lt is no common ion depression (Table 3). perhaps indicating mucleophilic attack on a contact ion pair. because we think that nucleophile attack on a solvent-separated ion pair would give a constant selectivity. and nucleophilic attack on a free cation should also show common ion rate depression.

The Grunwald-Winstein plots (Eqn. 1) of the rates in Table $I$ are presented in Figure I using the solvent ionizing power scale $I_{F r}$, based on 1-adamantyl bromide ${ }^{, i, k-9}$ Examination of Figure 1 shows that the plots for the three aqueous mixtures exhibit dispersions into two separate lines. The plots for all binary mixed solvents show a large $m$ value. $m=$ $0.7+(r>0.977)$ and the data point for $97 \%$ TFE solvent mixture shows only no significant deviation from the correlation of Gnunwald-Winstein plots for aqueous alcohol and acetone.

Rate ratios in two solvents which have same $Y_{B r}$ value. i.e. the same degree of solvent assistance for bond cleavage but different mucleophilicity provide measures of the minimum

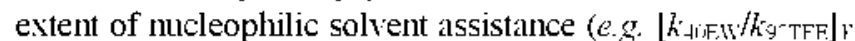
$=2.88 . \mathrm{EW}=$ ethanol-water) ${ }^{*}$ Thus the large $m$ values found $(0.7+)$ and the small value $(=2.88)$ of $k_{4 i \text { Fw }} / k_{9: T F F}$ shown in Table 2 imply that the solvolyses of 1 in the binary mixtures proceed by an $S_{* 1}$ pathway channel rather than by an $S_{* 2}$ channel (See Table 5). 
Table 5. Values of solvolysis rate ratios in $40 \% \mathrm{EtOH} / \mathrm{H}_{2} \mathrm{O}$ compared with $97 \%$ 1 $1 \% 1 / \mathrm{I}_{2} \mathrm{O}$ al $25^{\circ} \mathrm{C} \mathrm{C}$

\begin{tabular}{|c|c|c|c|}
\hline Substrates & kAcriw/kTT: & Substrates & HAOR: \\
\hline $\mathrm{Ph}_{2} \mathrm{CHCl}$ & 0.18 & 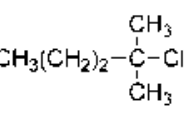 & 4.6 \\
\hline $\mathrm{CH}_{3} \mathrm{O} \phi \mathrm{CH}_{2} \mathrm{Cl}$ & 0.70 & $\begin{array}{c}\mathrm{CH}_{3} \\
\mathrm{H}_{3} \mathrm{C}-\mathrm{C} \equiv \underset{\mathrm{C}}{\mathrm{C}}-\mathrm{Cl} \\
\stackrel{\mathrm{C}}{\mathrm{C}} \mathrm{H}_{3}\end{array}$ & 7.1 \\
\hline $\begin{array}{c}\mathrm{Ph} \\
\mathrm{H}-\mathrm{C}_{\mathrm{I}}-\mathrm{Cl} \\
\mathrm{CH}_{3}\end{array}$ & 2.0 & $\mathrm{H} \quad \mathrm{H}^{-\mathrm{Cl}}$ & 1.9 \\
\hline $\begin{array}{c}\mathrm{CH}_{3} \\
\mathrm{H}_{3} \mathrm{C}-\mathrm{C}-\mathrm{Cl} \\
\stackrel{\mathrm{C}}{\mathrm{C}} \mathrm{H}_{3}\end{array}$ & 11 & & 1.48 \\
\hline
\end{tabular}

"I)ata from rets 23 and 28 .

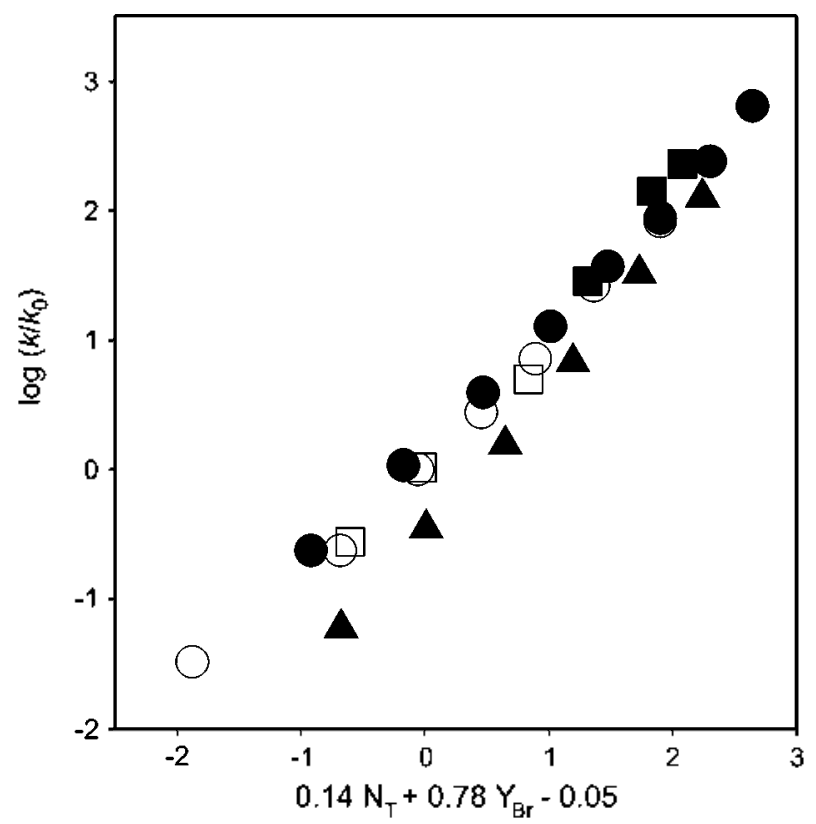

Figure 2, Ploc of log $\left(k h_{t}\right)$ for cinnamyl bromide agains $\left(0.14 \Lambda_{\mathrm{C}}+\right.$ $0.78 \mathrm{Y}_{\mathrm{Br}}-0.05$ ): $t=0.980$ (solvent codes: $\bullet$. methanol: $\because$. cthanol: ^ . acctone; $\boldsymbol{\square}$. TFE- $\mathrm{H}_{2} \mathrm{O}$; L . TFE- EtOH).

In order to examine the cause of this dispersion phenomenon. we correlated the rate data in Table 1 using Eqn. (2). The nucleophilicity parameter $\left(N_{\Gamma}\right)$ has been shown to give a very poor correlation when an $N_{\text {p }}$ term is added to the original Grunwald-Winstein Eqn. (1) (see Figure 2). Therefore such phenomenon can not be explained as dispersion effect caused by solvent nucleophilicity parameter.

Inclusion of the ring parameter (l) and nucleophilicity parameter $\left(N_{\mathrm{T}}\right)$ gives considerable improvement 10 correlations of the solvolyses of I (see Figure 3 ).

Therefore, this shows an importance of aromatic ring parameter rather than solvent nucleophilicity parameter for solvolysis of $\mathbf{1}$. Therefore such phenomenon can be explained as dispersion effects caused by aromatic ring. The dispersions in the Grunwald-Winstein correlations in the

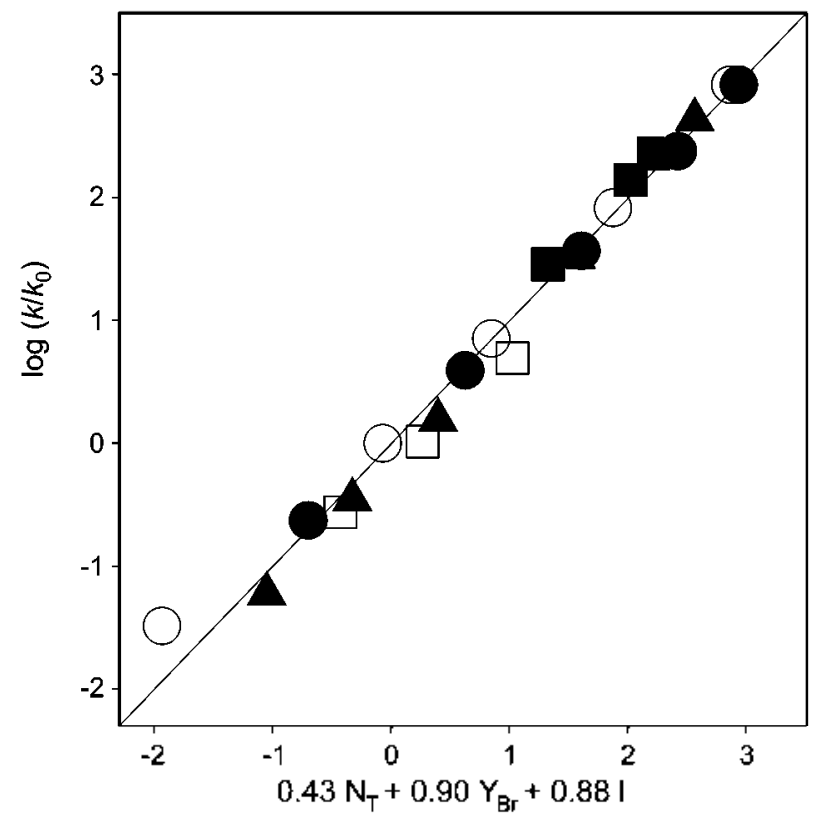

Figure 3. Plot of log $\left(k k_{n}\right)$ for cinnamyl bromide against $\left(0.43 \mathrm{~N}_{\mathrm{T}}\right.$ । $\left.0.90 \mathrm{Y}_{\mathrm{S}_{1}}-0.881-0.08\right) ; r=0.995$ (solvent codes: - methanol: . cthatiol: $\Delta$. acctonc; $\mathbf{\square}$. TFE- $\mathrm{H}_{2} \mathrm{O} ;$ । . . TFE-EtOH).

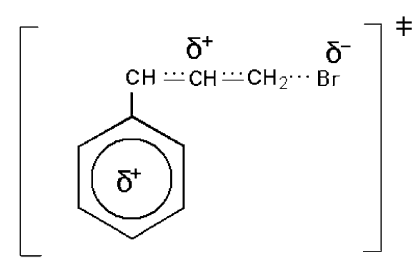

Scheme 2. Proposed Transition State Structure.

present studies are caused by the conjugation between the reaction center and aromatic ring through the conjugated $\mathrm{C}-\mathrm{C}$ double bond leading to the medium value of sensitivity of $/(h-0.88)$ in the equation (4). The through conjugation of the ring $\pi$ system with the reaction center has also been found in the solvolysis of phenyl chlorothionoformate ${ }^{29}$ and pyridinolysis of phenyl chloroformates. ${ }^{30}$ In this sludy this is interpreted to indicate the ovetlap of the reaction center which has strong cationic charge in the TS and aromatic ring $\pi$ system through $\mathrm{C}-\mathrm{C}$ double bond in the rate-limiting step. With use of the equation (4), the $m$ and $h$ values of 0.90 and 0.88 are obtained for the solvolyses of 1 (Fig. 3).

This study has shown that the magnitude of $m$ and $h$ values associated with a change of solvent composition is able to predict the $S_{* 1}$ reaction mechanism rather than an $S_{:} 2$ channel. In the TS, the cationic charge is delocalized to the ring. which causes to change the solvation of the ring and leads to a better correlations with the ring parameter, $I$.

$\Lambda$ ssuming general base catalyzed reactions as shown in Scheme 1 for nucleophilic attack on the substrate, the observed rate, $k_{\text {uts }}$ can be given for the reactions in acetonewater mixtures as Eqn. (7). ${ }^{19}$

$$
k_{0 \mathrm{bs}}=k_{\mathrm{uw}}[\text { water }]^{2}-k_{\mathrm{wa}}[\text { water }][\text { acetone }]+k_{\mathrm{as}}[\text { acetone }]^{2}
$$




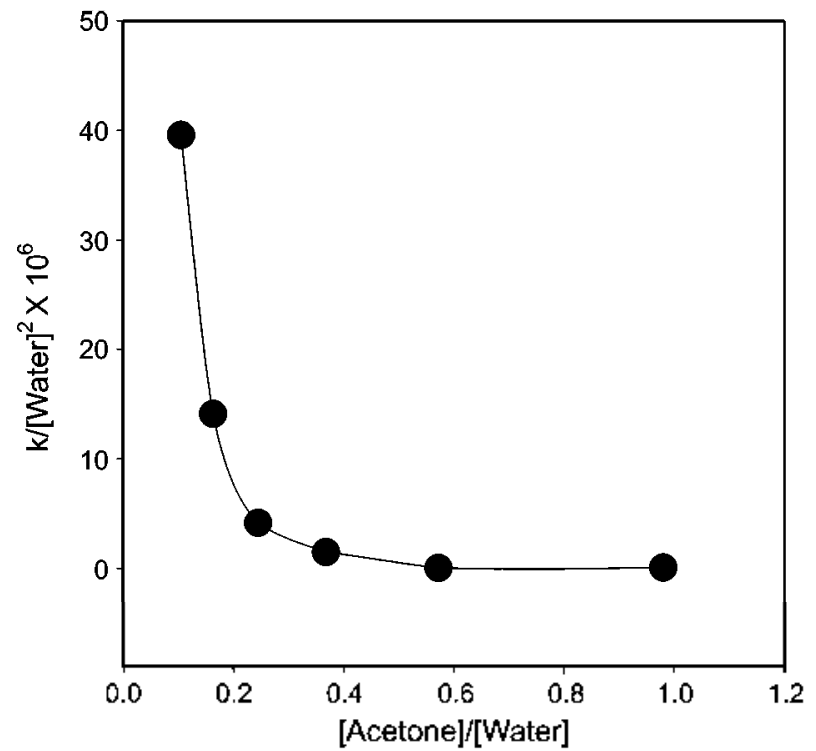

Figure 4. Plot of third-order rate constant versus [Acetone] [W'sler].

The third-order rate constant $k_{\text {ia }}$ can be obtained by the plot of $k_{\text {uts }} /$ [Water] $]^{2}$ versuss [acetone]/[Water] (Eqn. 8).

$$
k_{\text {obs }} /[\text { Water }]^{2}=k_{w w}+k_{w a}[\text { accione } / / \text { Water }]
$$

This type of plot showed a straight line of positive slope for the reactions proceeding with an $\mathrm{S}_{\mathbb{N}} 2$ mechanism (e.g. solvolysis of $p$-nitrophenyl chlorofomate). ${ }^{\mid S_{1}}$ The plot for the solvolysis of 1. however. leads to an exponential decay curve. Figure (t). This means that the rate is independent of the catalysis, $k_{\text {wa }}$ is non-existent and dependent on the ionizing power of the solvent. $Y$. In fact the plot of $\log k$ (third order) against volume percentage acetone shows a straight line of negative slope. which is exactly similar to that of $\log k$ versus $Y$ plot. We therefore conclude that the rate is soley dependent on $Y^{-}$(as required for an $\mathrm{S}_{\mathrm{N}} l$ reaction) and slow step of this reaction is ionization and there is no cataly sis and is not third order by solvent molecule.

The activation parameters for the reaction at $25^{\circ} \mathrm{C}$ are summarized in Table 4 . The small negative $\Delta s^{\ddagger}$ value and large positive $\Delta H^{-}$values are again in good agreement with our proposed $\mathrm{S}_{\mathrm{N}} \mathrm{l}$ reaction channels.

Rate-product correlations. Both the rate constants (Table 1) and \$ values [Eqn. (5). Table 6] increase as water is added to ethanol or to methanol. The increases in rates can be explained in various ways (e.g. by an increase in solvent ionizing power as the water content of the solvent increases). but the increase in $S$ is more difficult to explain." Competing second-order reactions would give constant $S$ values, in the absence of medium effects, ${ }^{31}$, $3=$ but the increase in $S \mathrm{~S}$ can be explained by a third-order mechanism. ${ }^{19}$

Plot of $1 / 5$ versus the molar ratio of alcohol/water [Eqn. (6)] are linear from $10 \%$ to at least $70 \%$ alcohol-water mixtures and thereafter curvature is significant (Fig. 5) which is consistent with increasing contributions from the $k_{\text {aล }}$ term (Scheme 1). Selectivities for methanol-water are significantly greater than for ethanol-water. and the slopes of $1 / \mathrm{S}$

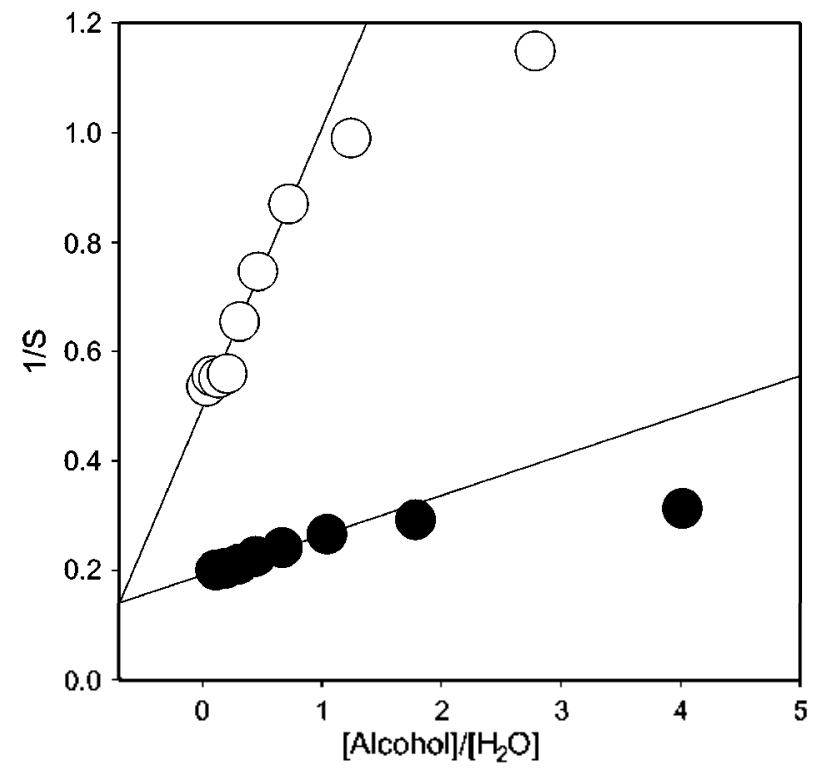

Figure 5. Plot of l/S v's. molar ratio of solvents versus [alcohol]/ [water], for solvolysis of cinnamyl bromide at 25 (solvent codes: - methanol: $\therefore$. ethanol) (ethanol: slop $=0.513$, intercept $=$ 0.497: methanol: slop $=0.00924$, intercept $=0.276$ ).

plots are lower for methanol-water than for ethanol-water (Fig. 5). These trends can be explained by the $k_{\text {ilw }}$ term. which compared with the $k_{\text {wel }}$ term. is greater for methanolwater than ethanol-water. The intercept of Eqn. (6) is determined by the ratio of third order rate constants $k_{\mathrm{w}} / k_{\mathrm{b} w}$. so nucleophilic attack by methanol assisted by water is 3.6 times more favourable than nucleophilic attack by water assisted by water.

The valid linear correlation obtained with eqn. (6) indicates that the product determining step. i.e. the attack of solvent on the cationic intermediate $\left(R^{\prime}\right)$. is catalysed by the cosolvent as in the $S_{\mathrm{N}} 2$ processes where the neutral substrate is attacked by the solvent. ${ }^{\mid \text {is }}$

\section{Experimental Section}

Material. Methanol, ethanol. and acetone were Merck GR grade $\left(<0.1 \% \mathrm{H}_{2} \mathrm{O}\right)$. and $\mathrm{CH}_{3} \mathrm{OD}$ were from Aldrich $(99.9 \%$

Table 6. Selectivities (S) for solvolyses of cimamyl bromide in acucous binany mixtures at $25^{\circ} \mathrm{C}$

\begin{tabular}{|c|c|c|c|c|}
\hline \multirow{2}{*}{$\mathrm{VVO}_{0}$} & \multicolumn{2}{|c|}{ Methanol Water } & \multicolumn{2}{|c|}{ F:thanol Waler } \\
\hline & [F:ther] [ Aleohol $]$ & $S$ & [Fither] $[$ Alcohol] & $s$ \\
\hline 90 & 12.8 & 3.19 & 2.43 & 0.87 \\
\hline 80 & 6.08 & 3.42 & 1.24 & 1.01 \\
\hline 70 & 3.90 & 3.76 & 0.829 & 1.15 \\
\hline 60 & 2.75 & 4.13 & 0.619 & 1.34 \\
\hline 30 & 1.97 & 4.43 & 0.473 & 1.53 \\
\hline 40 & 1.40 & 4.73 & 0.369 & 1.79 \\
\hline 30 & 0.937 & 4.91 & 0.241 & 1.99 \\
\hline 20 & 0.554 & 4.98 & 0.142 & 1.80 \\
\hline 10 & 0.239 & 4.83 & 0.0639 & 1.81 \\
\hline
\end{tabular}


Table 7. Correlation analy ses against different $I, X$ and $I$

\begin{tabular}{|c|c|c|c|c|c|}
\hline Parameters & $n$ & $r$ & $m(\text { s.d })^{a}$ & $I(\mathrm{~s} \cdot \mathrm{d})^{n t}$ & $h(\mathrm{~s} \cdot \mathrm{d})^{\prime \prime}$ \\
\hline $\bar{I}_{\Gamma_{1}}$ & 30 & 0.977 & $0.74(0.03)$ & & \\
\hline$I_{\mathrm{BS}} . \mathrm{X}_{\mathrm{OTS}}$ & 27 & 0.985 & $0.76(0.03)$ & $0.20(0.08)$ & \\
\hline$I_{\mathrm{S} 31} N_{\mathrm{T}}$ & 16 & 0.980 & $0.78(0.05)$ & $0.14(0.09)$ & \\
\hline$I_{[3 .} . I$ & 21 & 0.987 & $0.74(0.04)$ & & $0.16(0.21)$ \\
\hline$I_{\mathrm{B} 1} . \mathrm{K}_{\mathrm{TS}} I$ & 22 & 0.992 & $0.86(0.06)$ & $0.43(0.11)$ & $0.85(0.26)$ \\
\hline$I_{\mathrm{B}_{1} .} X_{\mathrm{T} .} I$ & 21 & 0.995 & $0.90(0.02)$ & $0.43(0.05)$ & $0.88(0.14)$ \\
\hline
\end{tabular}

"Standard der iation.

D). Distilled water was redistilled with Buchi Fontavapor 210 and treated using ELGA UHQ PS to obtain specific conductivity of less than $1 \times 10^{-6} \mathrm{mhos} / \mathrm{cm}$. Cinmamyl bromide (Aldrich GR grade. 99\%) was used without further purification.

Rate measurments and product selectivies. The rates were measured conductometrically at $25( \pm 0.03)^{\circ} \mathrm{C}$ at least in duplicate as described previously, ${ }^{1,2.33}$ with concentrations of substrate $c a \cdot 10^{-3} \mathrm{M}$.

The solvolysis products, ether and alcohol. were determined by HPLC analysis as described previously ${ }^{21}$ and the product-selectivities. S', were calculated from Eqn. (5). The $S$ values were calculated from the observed peak area ratios of ether and alcohol. divided by the appropriate response factor. For response calibrations, area ratios from solvolyses of 1 in pure alcohol and in $40 \%$ aceonitrile-water mistures were used. The eluent was $75 \%$ methanol-water mixture and the flow rate was adjusted to $1 \mathrm{~mL} \mathrm{~min}^{-1}$. The HPLC system was a Hew lett-Packard 1050 Series instrument, with $250 \times+$ mun Spherisorb ODS reversed column.

Acknow legement. This research was supported by a grant No. KOSEF 2001-1-12300-008-2 from the Korea Science and Engineering Foundation. We are also grateful to T. W. Bentley for helpful discussions.

\section{References}

1. Koo. I. S.: Bentlev: T. W.: Kang. D. H.: Lee. I. J. Chem. Soc. Perhin Trans. 2 1991. 175-179.

2. Bentley T: W. Koo. 1. S. J. Chem. Soc. Pentin Thoms. 21989. $1.385-1.392$

3. Bentlex, T. W. Carter, G. F. J. Im. (hem. Soc, 1982,104, 57415747.

4. Bentlev: T. W.: Harris. H. C.: Koo. I. S. J. Chem. Soc Perkm Troms. 2 1988. 783-789.

5. Bentley l. W.: Harris. H. C. J. Chem. Soc. Perhin Trons. 21986. $619-62+$

6. Koo, I. S.: An, S. K.: Yang, K: Koh, JI. J:- Choi, M. I.: I.ce, I.
Bull. Nonem Ch'm. Soc 2001. 22. 842-846.

7. Bentlex. T' W.: Bowen. C. T.: Morten. D. H.: Schlever. P'vR, $J$, Am. Chem. Sec. 1981. 103. 5466-5475.

8. Winstein, S. Grumuald, J. $J$. im (Them. Soc. 1948, 70. 846-854.

9. Bentley, T. W. Dau-Schmidt. J. P.: I.lewellytn. C.: Mayr. I I. J. O/g. (Wen 1992. 57. 2387-2392.

10. Winstein. S.: Fambery. A.: Grunwald. E. J. Am. Chem. Soc. 1957. 79. $4146-4155$.

11. Fainberg. A. H.: Winstein. S. $J$. fm. Chem. Soc, 1957. 79. 1957I608.

12. Winstein, S.: Grunwald. F... Jones, II. W. J. .1m. Chem. Soc. 1951. $73,2700-2707$.

13. Kevill. D. N.: Ismail. N. HJ: DSouza. M. I. J. Org. Chem. 1994. 59. 6303-6312.

14. Kevill. D. N.: D'Sonca. M. J. J. Chem. Soc. Rerkin Thons. 21995. 97.3-980.

15. Kevill, D. N.: D'Souza, M. J. J. Chem. Soc. Perkin Trans. 21997. 257-26.3.

16. Kevill. D. N.: Bond. M. W.: D'Solza. M. J. J. Org. Chem. 1997. 62. 7869-7871.

17. (a) Harris. J. M.: Clark. D. C.: Becker. A.: Fagan. I. F. $f$. Am. Chem. Soc. 1974, 96, 4478-4484: (b) I Iartis. I. M.: Becher. A. Fagatn. J. F.: Walden. Г. A. J. Am. Chem. Soc. 1974. 96. 44844489 .

18. (a) Karton. Y.: Pross. A. $J$ Chem. Soc Pertim Troms. 21977. 1860-1863: (b) McLennan. D. J.: Martin. P. L. J. Chem. Soc: Perhin Trans. 2 1982. 1099-1105.

19. (a) Bentley. T. W. Rvu. 7. II. J. Chem. Soc. Penhin Trans. 21994. 761-767; (b) Koo. I. S.: Yang. K.: Kang. K.: I ce, I.: Bentley. T. W. J. Chem. Soc. Ferkin Trans. 2 1998. 1179-118.

20. Song. B. D.: Jencks. Y. P. J. Am. Chem. Soc. 1989. HI. 84708479 .

21. (a) Bentley. T. W.: Jones. R. O. J. Chom. Soc lerkin Troms. 2 1993, 2351-2.357: (b) Bentler, T. W.: Jones, R. O.: Kon. I. S. J. Chen. Soc. Perhin Trans 2 1994. 753-759: (c) Jones. R. O. M. Phil. Thesis Uniticisity of Wales: 1991

22. Koo. 1. S.: Yang. K.: Kang. K.: Lee. I. Bull. Nonem Chm. Soc. 1998. 19.968-973

23. (a) Bentley. T. W.: Koo. I. S.: Norman. S. J. Ory. Chem. 1991. 56. 1604-1609: (b) Koo. I. S.: An. S. K.: Yang, K.: I.ce, I.; Bentley, T. W. J. Phy Oig (hem. 2002, 15, 758-764.

24. I.iu, K. T.: Duann, Y. F.: IIou, S. H. J. Chem. Soc. Perkin Trats ? 1998. $2181-2185$.

25. Oh. J.: Yang. K.: Koo. I. S.: Lee. I. $J$. Chem. Res. 1993. 310-311.

26. Bentley. T. W.: Harris. H. C. J. Org. Chem. 1988. 53. 724-728.

27. Gold. V.: Grist. S. J. (hem. Soc B 1971, 2285-2286.

28. Bentley, T. W. I.lewllyn, G... Rỹu. 7. II. J. Org. ( $h^{\prime} m .1998 .63$. $4654-4659$

29. Koo. L. S.: Yang. K.: Kang. D. H.: Park. H. J.: Kang. K.: Lee. I. Bull. Lonem Chem Soc 1999. 20. 577-580.

30. Kol. H. I.: Lee. H. C.: Lee. H. W. Lee. I. Bull Korean Chem. Soc. $1996,17.712-715$

31. Bentle, T. W.: Fibdon, D.: J Icwellyn. G..: Abduljaber. M. IT.: Miller, B.: Kevill, D. N. J. Chem. Dalon Traws. 1997. 3819-3825.

32. Ta-Sluma. R.: Rappon L. Ath: Phss. Org. Chem 1992. 27. 239.

33. Yang. K.: Koo. I. S.: Lee. I.: Jo. D.-S. Bull Norem Chem. Soc: 1994. 15. 280-284. 